\title{
Methodological Proposal for the Execution of Virtual and Face-to-Face Surveys for the Implementation of a Public Bicycle System, Case Study: Villavicencio, Colombia
}

\author{
William Castro', Diego A. Escobar ${ }^{2 *}$ and Laura D. Ramírez ${ }^{3}$ \\ 'Universidad Nacional de Colombia - Sede Bogotá. Facultad de Ingeniería. Departamento de Ingeniería Civil \\ y Agrícola. Ciudad Universitaria edificio 214 Oficina 415, Bogotá, 111321, Colombia; wcastrog@unal.edu.co \\ ${ }^{2}$ Universidad Nacional de Colombia - Sede Manizales. Facultad de Ingeniería y Arquitectura. Departamento \\ de Ingeniería Civil. Cra 27 \# 64-60, Manizales, 170004, Colombia; daescobarga@unal.edu.co \\ ${ }^{3}$ Universidad Nacional de Colombia, Sede Bogotá. Facultad de Ingeniería, Departamento de Ingeniería Civil y \\ Agrícola, Programa de Investigación en Tránsito y Transporte - PIT. Ciudad Universitaria edificio 214 oficina 321, \\ Bogotá, 111321, Colombia; Idramirezl@unal.edu.co
}

\begin{abstract}
Objectives: The purpose of this research is to compare the results of the face-to-face and virtual modes for mixed data surveys in the case study of the implementation of a Public Bicycle System (PBS) in Villavicencio, according to a revised methodology in other regions of the world such as the United Kingdom, the United States and Australia. Methods/Analysis: The methodology in this investigation is composed of Preliminary investigation; Processing of primary information and comparison with case studies; Analysis of supply and demand of the PBS; finally comparative analysis of survey methodology for characterization of users of a PBS. Findings: Authors find that According to the review of modes for conducting surveys (e-mail, postal mail and telephone call) used in three regions of the world, the most used is the virtual one. Therefore, it is recommended that, if this method is chosen, it will be supported with face-to-face surveys for these populations to disseminate the survey for more than a month and motivate them with some compensation. In addition, it is established that the people most willing to use the PBS are those who are currently mobilized in non-motorized ways. Application/ Improvements: It is important to know that each PBS must correspond to a specific analysis of the region where it is implemented. That it corresponds to a mixed data survey to have a complete characterization of the sample of the surveyed population and of the possible users of the Public Bicycle System.
\end{abstract}

Keywords: Face-to-Face Survey, Origin-Destination Studies, Public Bicycles, Virtual Survey

\section{Introduction}

A system of public or shared bicycles is based on the loan or temporary rental of this type of vehicle. It aims to promote its urban use in short trips (usually around 30 minutes), between previously registered persons and identified. Bicycles must be taken from a pre-established station and returned after its use to the same or another station, all within the operating area $\stackrel{1}{\text {. As populations }}$ grow, traffic congestion increases, the price of fuel rises and global awareness of climate change escalates, which is why it has become necessary for world leaders to find new modes of transport and better adaptation of existing modes to mobilize people in an increasingly ecological, efficient and economically viable way. A real option is the

*Author for correspondence 
shared use of bicycles, which is evolving rapidly to adapt to the needs of the 21 st century ${ }^{2}$.

Latin America presents an increase in motorization due to the growth of the Gross Domestic Product (GDP) of the countries of the region. At the same time, there is a worrying increase in the use of motorcycles in several cities in this part of the continent and a consequent loss of demand in public and non-motorized transport systems (walking and cycling) ${ }^{\underline{3}}$. In Colombia there is a successful case with planned operation continuity for 2030 called Encicla ${ }^{4}$, which is the Public Bicycle System (PBS) of the Aburra Valley in Antioquia. Other systems as such implemented are in the cities of Manizales ${ }^{5,6}$, Popayán and Bogotá, where there has not been such a satisfactory operation or where it has had low coverage. Considering this, it is important to establish that each PBS must correspond to a specific analysis of the region where it is to be implemented, taking into account the social environment, the financial resource, the route needs of the users and the continuity of the administration of the system.

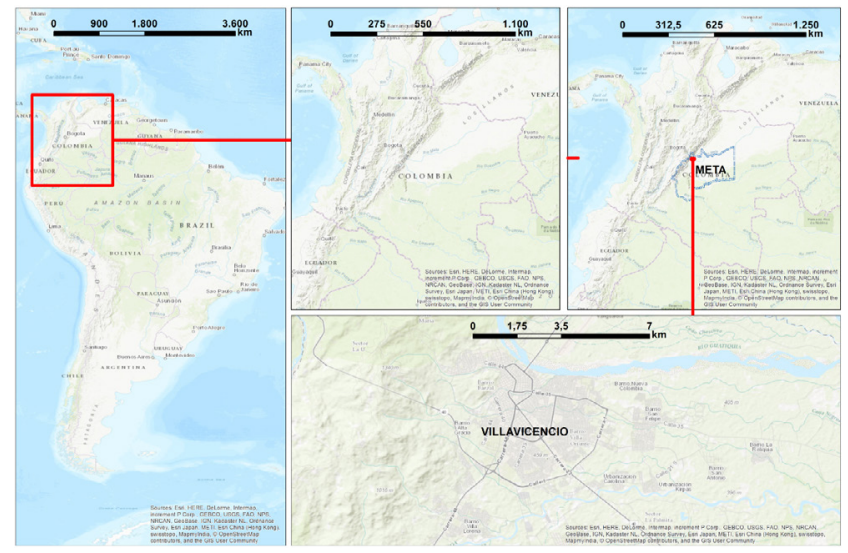

Figure 1. Geographic location of the municipality of Villavicencio.

Villavicencio, the municipality in which the case study is conducted, is the capital of the department of Meta. It is located in the center-eastern region of Colombia (Figure 1) in the foothills of the eastern cordillera of the Andes, at an average altitude of 467 meters above sea level. It has a total extension of $1,328 \mathrm{~km} 2$. The study area covers the urban and rural area of the municipality, within which two geographical regions stand out: the first located in the west and northwest of the municipality that corresponds to the mountainous formation generated by the Eastern Cordillera, and the second region is the plain towards the east and northeast that is delimited by the Guayuriba
River $^{7}$. In recent years, Villavicencio has had a boom in the implementation of cyclo-infrastructure, recreation campaigns, BMX groups and groups promoting the use of bicycles. This has raised the need to propose strategic mobility options that involve multimodal use and tourism promotion, such as a PBS.

To characterize and set a dimension to the possible number of users of the PBS, and also to recognize the Origin-Destination (O-D) that is predominant in the mobility dynamics of the municipality, a survey format with mixed data was conducted face-to-face and virtually. These surveys have two classifications according to the type of preference: Revealed Preferences (RP) and Declared Preferences (DP). RPs expresses the observed decisions of individuals based on the main attributes that explain the usefulness of different transportation alternatives in real market situations. On the other hand, the DPs try to infer the individual preferences for a series of hypothetical situations constructed by the researcher, trying to define the characteristics of the alternatives as realistically as possible ${ }^{8}$. Because each approach has advantages and disadvantages, the combination of both types of data (modeling with mixed data) is recommended in order to take advantage of its virtues and reduce the disadvantages derived from the use of such data sources individually ${ }^{2}$. This survey was carried out face-to-face and virtually to the population of the municipality of Villavicencio, Meta, obtaining results that allowed to compare other case studies in which surveys were conducted to users or potential users of a Public or Shared Bicycle System.

\section{Methodology}

The methodology in this investigation is composed of 4 main phases that are shown in Figure 2: 1. Preliminary investigation; 2. Processing of primary information and comparison with case studies; 3 . Analysis of supply and demand of the PBS; and 4. Comparative analysis of survey methodology for characterization of users of a PBS.

\subsection{Stage 1. Preliminary Investigation}

To characterize bicycle sharing, surveys are essential to understand who is using the bicycle at that time and the other modes of transportation used by potential PBS users. In structuring the survey, it is important to recognize the current social and cyclical infrastructure characteristics of the area. In this case, the previous review of secondary 
information about public policies to promote bicycle use, as well as its collective promoters, the current management of road safety for bicycle users and the volumes of vehicles in specific stations that took place in the territory where the PBS will be implemented must be considered. The survey developed for a PBS must take into account whether the population has already approached or used the concept, as well as taking into account the period of time in which the survey is conducted: before, during or after the implementation of the PBS. The structuring and its processing are fundamental to generate a model that characterizes the population where it will be carried out. For this, a PBS model from Ningbo, China ${ }^{10}$ was reviewed, as is shown in Figure 3.

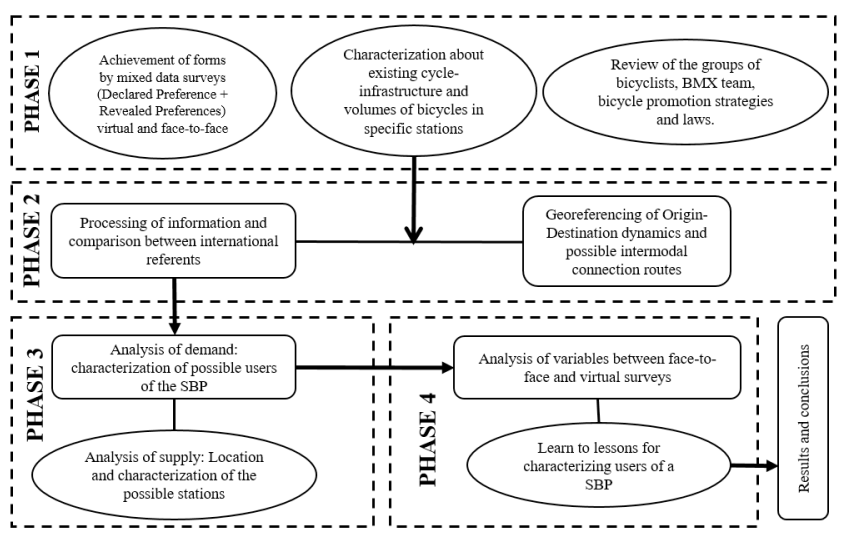

Figure 2. Methodology of the investigation in the case study.

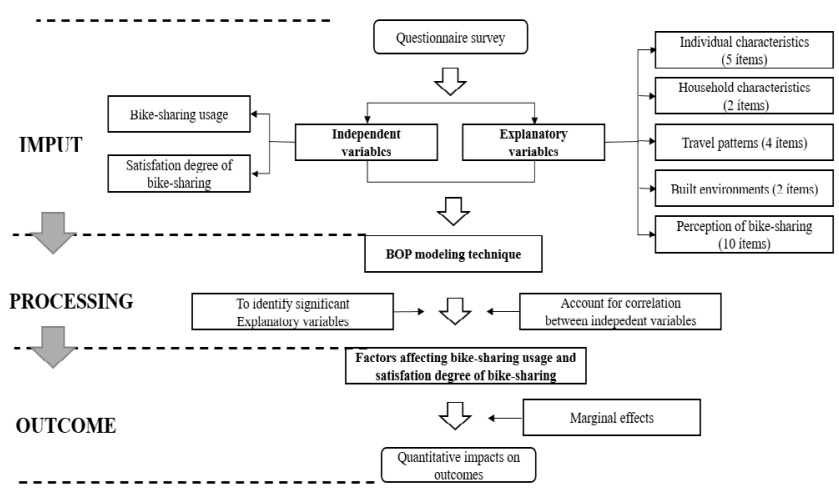

Figure 3. Survey methodology for users of shared bicycles in Ningbo, China.

The inputs of this model are independent and explanatory variables determined from a survey used to collect data on the use and satisfaction of shared bicycles. Likewise, the explanatory variables that include the individual characteristics, the home characteristics, the travel patterns, the built environments and the perception of the shared use of bicycles are collected through the survey. In the processing, the Bivariate Ordered Provit (BOP) modeling technique was used to identify the significant factors that affect bicycle sharing and the degree of satisfaction ${ }^{10}$. A preliminary testing of the survey is an opportunity to correct and evaluate the processing before doing it in the final population sample. During the pre-test of a survey, at least the following questions should be asked: Are there instructions to complete the survey clearly? Are the questions easy to understand? Do the respondents or pollsters understand how to indicate answers? Are the answer choices exhaustive? Are the questions poorly written or misleading? Are there any missing questions? Did the respondents have enough time to complete the survey? Are the questions as «neutral» as possible ${ }^{11}$ ? For the case study in Villavicencio, the final form was made in November 2017, after conducting a previous pilot test. The final form and the procedure that includes virtual and face-to-face modes correspond to the flow diagram of Figure 4.

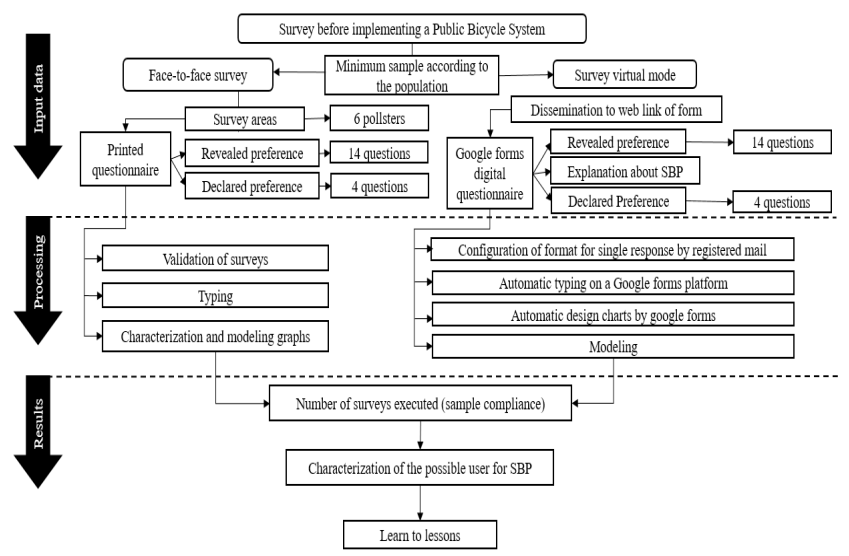

Figure 4. Methodology of surveys carried out to implement a system of shared bicycles in Villavicencio.

\subsection{Stage 2. Processing of Primary Information and Comparison with Case Studies}

The georeferencing of Origin-Destination of the surveys allows recognizing the dynamics of mobility of the inhabitants of the municipality, alongwith the results of the Hour of Maximum Demand of the vehicular volumes and the modeling of the possible routes of intermodal connection that the PBS could have. Additionally, a comparison is made between the case studies of other SBPs and their methodology regarding surveys. Likewise, a compari- 
son of methodologies used throughout the last 10 years in some regions of the world in periods before, after and during the implementation of the PBS is made, allowing comparing and discussing the results of the case study.

\subsection{Stage 3. Analysis of Supply and Demand of the PBS}

The analysis of the demand allows to characterize, according to the sample of mixed data surveys, aspects such as origins, destinations, perceptions or motivations to use the PBS and, in turn, it is the input of data to evaluate the supply necessary to determine the number of anchors, fleet by station, quantity and location of stations in the first stage of the project.

\subsection{Stage 4. Comparative Analysis of the Survey Methodology for the Characterization of the PBS Users}

Due to the fact that a mixed data survey was conducted in two modes, virtual and face-to-face, variables and lessons learned were identified for future surveys focused on characterizing possible users of a PBS.

\section{Results and Discussion}

\subsection{Definition of the Sample Size}

For the determination of the minimum number of surveys, the following formula was used to calculate the sample $\frac{12}{}$.

$$
n=\frac{N \sigma^{2} Z^{2}}{(N-1) e^{2}+\sigma^{2} Z^{2}}
$$

Where:

$\mathrm{n}=$ Sample size

$\mathrm{N}=$ Population size

$\sigma=$ standard deviation, considered a constant value of 0,5 .

$\mathrm{Z}=$ value obtained by trust levels

$\mathrm{e}=$ acceptable sample error limit

The population of Villavicencio municipality ${ }^{7}$ corresponds to 452,472 inhabitants, therefore a confidence percentage of $95 \%$ was chosen, establishing the parameters used in Table 1. Taking into account the above, the minimum number of surveys to be carried out was 384 . However, 807 printed surveys and 75 surveys were carried out in virtual format using Google Forms.
Table 1. Parameters for estimating the minimum sample

\begin{tabular}{|l|l|}
\hline $\mathrm{N}$ & 452,472 \\
\hline$\sigma$ & 0.5 \\
\hline $\mathrm{Z}$ & 1.96 \\
\hline $\mathrm{e}$ & 0.05 \\
\hline $\mathrm{n}$ & 383.8 \\
\hline
\end{tabular}

\subsection{Preparation of the Survey}

Interception surveys are a proven method to collect information about the decisions people make in transport and how they perceive it, what they think and what they want. When it comes to public bicycles and using them, the data collected is essential for planners, advocates, public health officials, marketing teams and others as they implement public bicycle systems or promote bicycle infrastructure; design policies and programs; and the potential users of the bicycle ${ }^{13}$. In the case of Villavicencio, the same Survey was conducted. The questions asked are presented in Figure 5 with the respective order and their discrimination of revealed and declared preference component. The Survey consists of 18 questions with an introductory explanation on the public or shared bicycle systems to guide the respondent from the beginning of phase II.

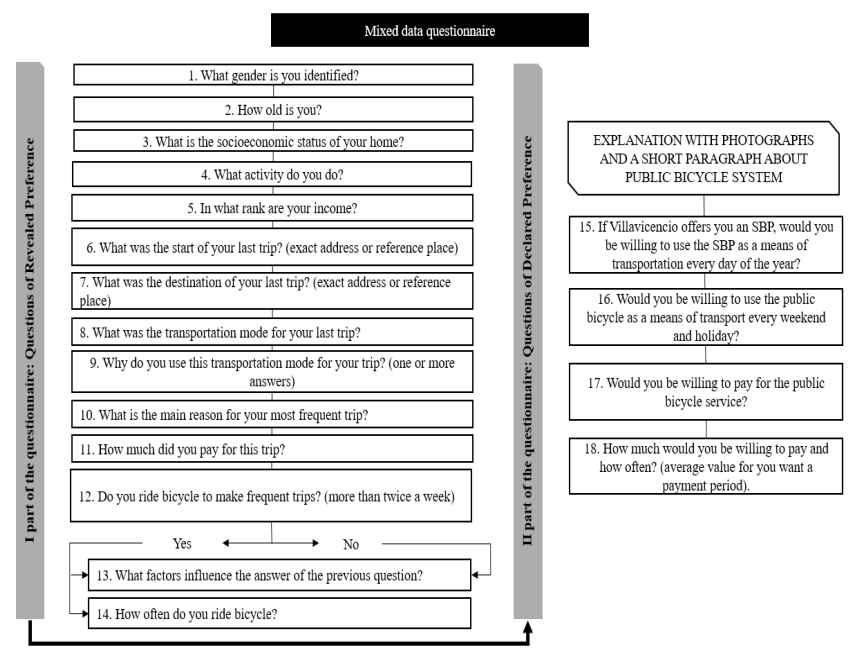

Figure 5. Mixed data survey carried out to implement the Villavicencio PBS.

\subsection{Method for Conducting the Survey}

A review of case studies was carried out for the execution of surveys of PBS, as presented in Table 2. The survey for users of the PBS in the United Kingdom was developed by 
Table 2. Case studies of modes to conduct surveys

\begin{tabular}{|l|l|l|l|}
\hline Country orregion & United Kingdom & United States & Australia \\
\hline Case study & United Kingdom's PBS & $\begin{array}{l}\text { Sacramento, West } \\
\text { Sacramento and Davis' PBS }\end{array}$ & Sidney Cycling Survey 2011 \\
\hline Mode & E-mail & $\begin{array}{l}\text { E-mail with raffle for } \\
\text { answering the survey, with } \\
\text { the option to send the } \\
\text { answers by postal mail. }\end{array}$ & $\begin{array}{l}\text { Telephone, computer- } \\
\text { assisted (CATI) }\end{array}$ \\
\hline Contucting period & July 12th, 2016 & April 30th, 2016 & November 14th, 2011 \\
\cline { 2 - 4 } & September 18th 2016 & May 12th, 2016 & December 3rd, 2011 \\
\hline $\begin{array}{l}\text { State of the PBS at the } \\
\text { moment of conducting } \\
\text { the survey }\end{array}$ & Implemented & $\begin{array}{l}\text { Before implementing the } \\
\text { system }\end{array}$ & $\begin{array}{l}\text { Does not apply, only cyclist } \\
\text { user }\end{array}$ \\
\hline
\end{tabular}

Bikeplus with support from the operator of the PBS and the local representative of the authority. The survey was designed for each specific city and includes a satisfaction survey. These were distributed to all users via email between July 12, 2016, and September 18, 2016. 891 responses were received from 17 systems in the United Kingdom ${ }^{14}$. In Sacramento, West Sacramento and Davis the survey was conducted in April 2016 (before the PBS) and they waited to conduct the survey a few months after the launch of the large-scale PBC in 2018 (after the PBS). From the address database for these areas, they randomly selected 5,000 and 2,000 addresses, respectively. The recruitment letter invited residents to participate in an online survey and provided the URL for the survey site. They offered prospective participants the chance to enter a cash prize drawing for ten $\$ 100$ gift cards if they completed the survey on April 30, 2016. The recruitment letter stated that only residents over 18 years old could participate in the study, and asked the possible participants who did not want or could not complete the survey to contact us and request a physical copy of it by post with postage paid on return. They sent reminder postcards a week after the initial survey, recruitment letters and extended the deadline to participate in the draw until May 12, 2016. As a result, an $11.5 \%$ response rate was achieved for Sacramento, $8 \%$ for West Sacramento and 20\% for Davis, for an overall rate of $14 \%$. The online survey was scheduled using the Qualtrics software. A small number of physical copies of the survey were sent and returned by mail ${ }^{15}$.

The strategic business plan NSW 2021 sets a goal for more than double the participation in bicycle use between trips of up to $10 \mathrm{~km}$ in the Greater Sydney Metropolitan Area by the year 2016. To achieve this goal, Roads and Maritime Services (RMS) and the Bureau of Transport
Statistics (BTS) commissioned Sinclair Knight Merz to develop a survey method to monitor performance towards this goal. The 2011 Sydney Cycling Survey was conducted through Computer-Assisted Telephone Interviews (CATI), chosen as the most cost-effective survey method, offering the best opportunity to obtain timely data and have the greatest control over sampling biases. The survey was conducted over a three-week period from November 14 to December 3, 2011. Telephone interviews were conducted by Market Solutions on behalf of the project team. All the interviewers had experience in conducting telephone interviews and had been trained on the objectives of the survey before starting field work $\frac{16}{}$.

According to the case studies and feasibility of conducting surveys in Villavicencio, the surveys were carried out in two ways, virtual and face-to-face. For the face-toface survey, six (6) pollsters were designated, located at points of public attraction and areas of multiple activities in the municipality with specific hours from November 20 to November 26, 2017, with a total of 807 valid surveys. At the same time, the Google Forms survey was carried out and it was configured in such a way that it only allowed one answer per email account to avoid duplication of the form, which was disseminated through the webpage of the City Hall of Villavicencio during the month of November 2017, with a total of 76 forms.

\subsection{Characterization of the Surveyed Sample}

According to socioeconomic conditions, in Colombia there is a method of stratification of buildings for the collection of public services and identification of purchasing power. Therefore, it is an indispensable question to iden- 
tify to which stratum respondents correspond and how the sample is distributed according to their purchasing power or economic strata. The results of the case study in Villavicencio are shown in Figure 6. On the other hand, virtual surveys do not guarantee that the population of extreme socioeconomic strata responds to the survey, unlike the one done face-to-face, which allowed identifying the survey areas where it could be guaranteed that people from extreme socio-economic strata (1 and 6, Table 3) could be surveyed.

Table 3. Stratification in Colombia ${ }^{17}$

\begin{tabular}{|l|l|}
\hline Stratum & Subsidies percentage (Factor) \\
\hline 1: low - low & 0,50 (Subsidies until 50\%) \\
\hline 2: low & 0,60 (Subsidies until 40\%) \\
\hline 3: medium - low & 0,85 (Subsidies until 15\%) \\
\hline 4: medium & $\begin{array}{l}1,00 \text { (no subsidies and no } \\
\text { contributions) }\end{array}$ \\
\hline 5: medium-high & 1,20 (contributions until 20\%) \\
\hline 6: high & 1,20 (contributions until 20\%) \\
\hline
\end{tabular}

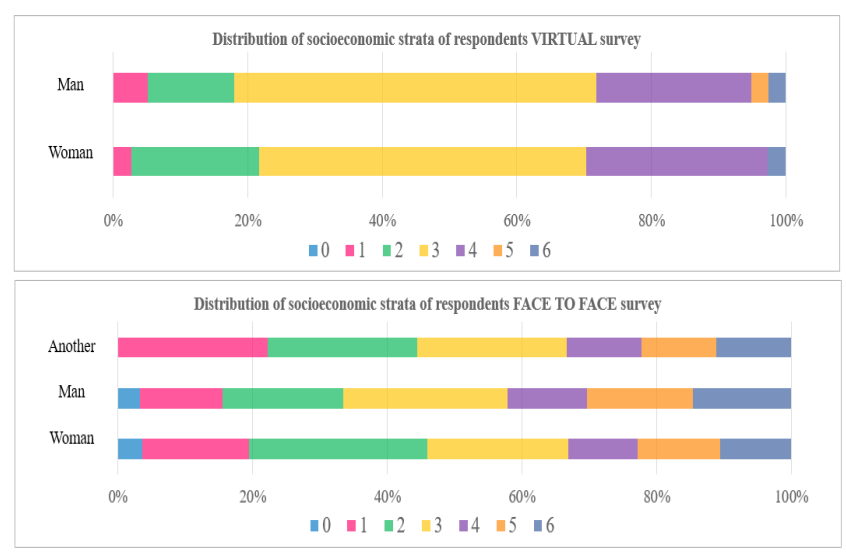

Figure 6. Virtual and face-to-face surveys according to socioeconomic status and gender.

In order to recognize the LGBTI population, the gender «other» was included in the survey as indicated in Table 4. The responses according to the gender of men and women are proportional in both modes. However, participation of those who identified with another gender is disproportionately minimal against the others.

\subsection{Characterization of the Population of Potential PBS Users}

According to the mode of transport currently used by the respondent: It is important to recognize which current modes of transport would be replaced by the PBS alternative transport mode. It is important to recognize that respondents in the face-to-face mode who are currently traveling by bicycle would choose the PBS that is offered, and in the virtual survey, those currently on foot would all use the proposed PBS (Figure 7).

Table 4. Surveyed by gender

\begin{tabular}{|l|l|l|}
\hline Gender & Face-to face & Virtual \\
\hline Man & 431 & 39 \\
\hline Woman & 367 & 37 \\
\hline Other & 9 & 0 \\
\hline
\end{tabular}

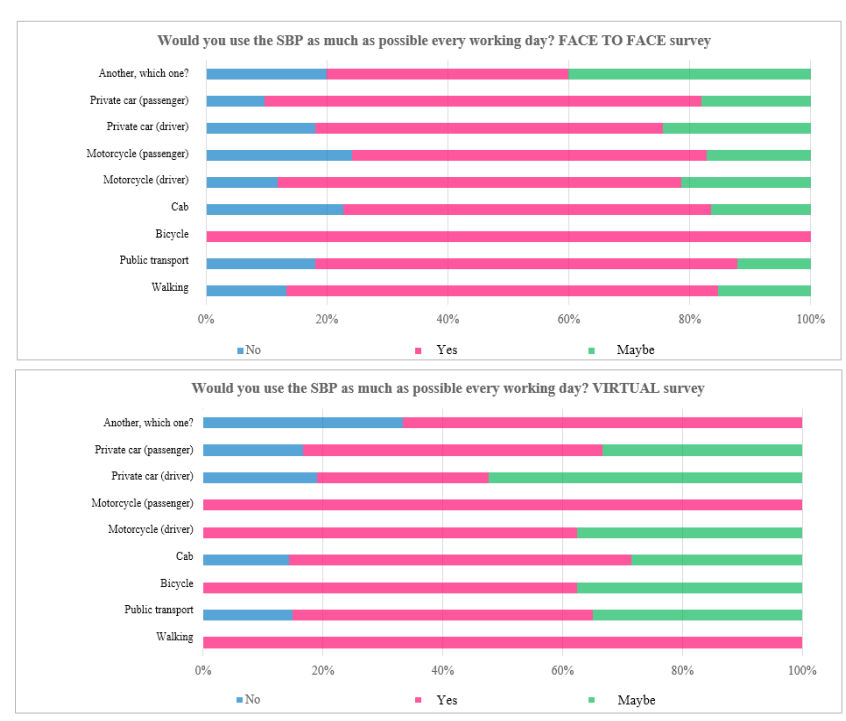

Figure 7. Respondents who would use the PBS according to the current mode of transport.

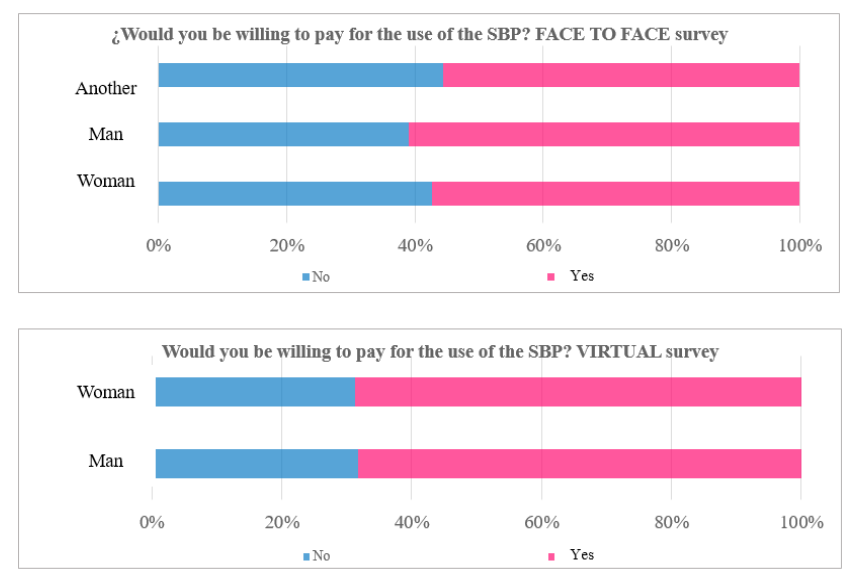

Figure 8. Willingness to pay for the use of the system and gender with which the user is identified.

According to the willingness to pay for the use of the system and gender with which the respondent is identified: 
Although the PBS should mostly be subsidized by the state, by publicity or with private financing, it is important to identify who would be willing to pay for the use of the system. It is also recommended to not exceed the cost of the public transport fare per daily trip in the system. The results are identified in Figure 8.

Bicycle sharing is a disruptive service in the collaborative economy and, like all new services, there is a learning curve. But of the 106,055 trips in 2015 , only $10,930(10 \%)$ incurred a usage fee; of those 10,930 trips, only $2 \%$ (224) requested a refund, which means that the remaining $8 \%$ $(10,706$ trips) intentionally extended their time.

\subsection{Characterization of the Conditions Due to which the Respondents do not Currently use Bicycles}

This characterization allows identifying which are the priorities to maintain the users in the future system of public bicycles, besides recognizing the current conditions for the cyclists (Figure 9).

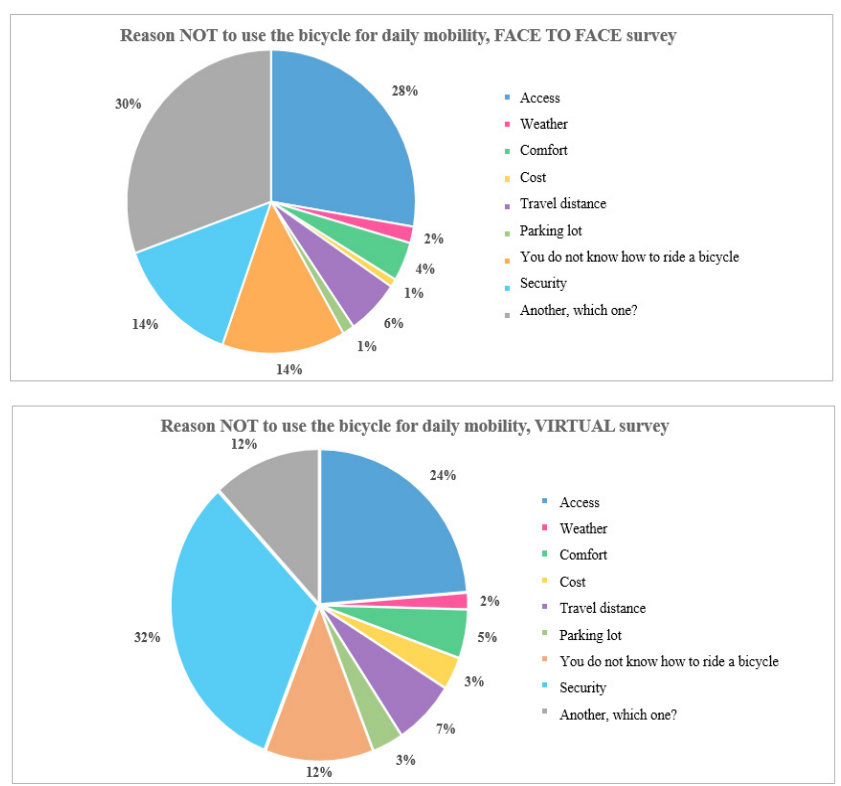

Figure 9. Reasons for which the respondent do NOT currently use bicycles.

In both types of survey (virtual and face-to-face), the reasons why users do not currently use bicycles in Villavicencio are access, security and others. The reasons identified as «others» were: because they do not own a bicycle, they do not like it, they cannot do it for health reasons or they do not have enough time (Figure 10). The reasons why bicycles are used in greater percentage are access, comfort and others. The reasons for which bicycles were used, identified as "others", were: sport, recreation, pleasure and health care.

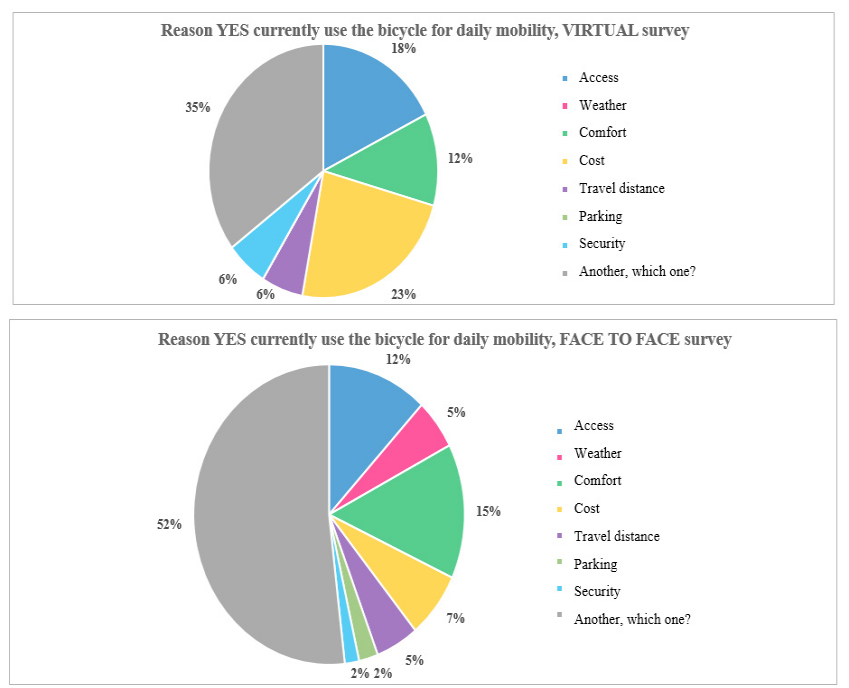

Figure 10. Reasons why the respondent is currently using bicycles.

\section{Conclusions}

For PBS surveys before implementation, it is suggested that the Survey include questions of declared and revealed preference, that is, that it corresponds to a mixed data Survey to have a complete characterization of the sample of the surveyed population and of the possible users of the public bicycle system.

It is important to conduct a pilot survey before conducting the final survey on the population sample. It is recommended that the Survey be carried out at the same time that its respective numbered format or processing method was generated in the face-to-face survey. The virtual survey in the format of Google Forms provides an automatic processing of graphics but it is recommended to use the database generated by Google Forms and process the information according to what one prefers to characterize.

According to the review of modes for conducting surveys (e-mail, postal mail and telephone call) used in three regions of the world, the most used is the virtual one. However, in Villavicencio and in most municipalities of Colombia, access of the lowest socioeconomic strata to the virtual format is difficult and the higher strata are interested in accessing it. Therefore, it is recommended 
that, if this method is chosen, it will be supported with face-to-face surveys for these populations to disseminate the Survey for more than a month and motivate them with some compensation.

Finally, it is established that the people most willing to use the PBC are those who are currently mobilized in non-motorized ways. However, to have greater environmental benefits, it is suggested to generate campaigns or strategies, infrastructure improvements or incentives for users of motorized modes to prefer the $\mathrm{PBC}$ to a greater extent.

\section{Acknowledgments}

To the National University of Colombia for its decided support in the development of this investigation

\section{References}

1. Montezuma R. Sistemas Públicos de Bicicletas para América Latina. Guía práctica para implementación. Bogotá: CAF; Fundación Ciudad Humana; 2015.

2. DeMaio P. Bike-sharing: History, Impacts, Journal of Public Transportation. 2009; 12(4):41-56. https://doi. org/10.5038/2375-0901.12.4.3.

3. Pardo CF, Revisión de los Sistemas de Bicicletas Públicas para América Latina: beneficios y obstaculos. Clean Air Institute. Washington D.C.; 2012 .

4. Valle de Aburrá AM. Plan Maestro Metropolitano de la bicicleta del Valle de Aburra. Medellín: Tranvías S.A.S. Transporte y vías; 2015. p. 1-158.

5. Zuluaga J, Escobar D, Younes C. A GIS approach based on user location to evaluate a bike-sharing program, DYNA. 2018; 85(204):257-63. https://doi.org/10.15446/dyna.v85n204.67670.

6. Acceso peatonal y cobertura de las estaciones del sistema de bicicletas públicas de la ciudad de Manizales. Date accessed: 12/01/2017. http://www.revistaespacios.com/ a17v38n29/17382908.html.
7. Alcaldía de Villavicencio, ALCALDÍA DE VILLAVICENCIO - META Unidos Podemos. Date accessed: 18/07/2017. http://www.villavicencio.gov.co/MiMunicipio/Paginas/ Informacion-del-Municipio.aspx.

8. Raquel EE, Juan de Dios OS, García RC. Dise-o de preferencias declaradas para analizar la demanda Dise-o de preferencias declaradas para analizar la demanda, Estudiosde Economía Aplicada. 2004; 22(3):759-93.

9. Bradley M. Estimation of logit choice models using mixed stated preference and revealed preference information, Understanding Travel Behaviour in an Era of Change. 1977; 209-31.

10. Guo Y, Zhou J, Wu Y, Li Z. Identifying the factors affecting bike-sharing usage and degree of satisfaction in Ningbo, China, PLOS ONE. 2017; 12(9):e0185100. https:// doi.org/10.1371/journal.pone.0185100. PMid: 28934321, PMCid: PMC5608320.

11. Baltes MR. Customer surveying for public transit: A design manual for on-board surveys. National Center for Transit Research (NCTR). Washington D.C.; 2002. p. 1-55.

12. Montesano D. Manual del protocolo de investigación. 1st Edition. Intersistemas. 1999. PMCid: PMC24139.

13. NACTO. Bike Share Intercept survey toolkit. National Association of City Transportation Officials. New York; 2016.

14. Public Bike Share Users Survey Results. Date accessed: 09/2017. https://como.org.uk/wp-content/ uploads/2018/06/Public-Bike-Share-User-Survey-2017A4-WEB-1.pdf.

15. Handy S, Heckathorn D. Sacramento area travel survey: Before bike share. A research report from the National Center for Sustainable Transportation. UCDAVIS Institute of Transportation Studies; 2017. p. 1-28. PMid: 28979528, PMCid: PMC5606368.

16. Transport for NSW and Bureau of Transport Statistics. Sydney Cycling Survey 2011 Methods and Findings. Sydney: Transport for NSW; 2012. p. 1-39.

17. Alzate MC. La estratificación socioeconómica para el cobro de los servicios públicos domiciliarios en Colombia: ¿Solidaridad o facalización? Estudios Y Perspectivas Oficina De La Cepal En Bogotá; 2006. p. 1-101. 